\title{
Cultura escolar e questões em gênero e sexualidade O delicado equilíbrio entre cumprir, transgredir e resistir
}

\section{School Culture and Issues on Gender and Sexuality:}

The delicate balance between accomplishing, transgressing, and resisting

\section{Cultura escolar y cuestiones en género y sexualidad: \\ El delicado equilibrio entre cumplir, transgredir y resistir}

FERNANDO SEFFNER

Universidade Federal do Rio Grande do Sul, Porto Alegre- RS, Brasil.

RESUMO: A atuação docente em questões de gênero e sexualidade na escola pública comporta um conjunto de delicados equilíbrios. Envolve reconhecer que as categorias conceituais que utilizamos para falar desses temas são também categorias de ação política e de regramento moral. O artigo analisa estas questões a partir da etnografia de cenas escolares, e mostra a importância da abordagem de gênero e sexualidade no currículo. Com isso, se posiciona contrário aos movimentos que buscam cercear a liberdade de ensinar e afirmam que tais temas seriam da órbita exclusiva da família e das religiões na formação dos jovens.

Palauras-chave: Gênero. Sexualidade. Escola pública. Formação de professores.

\begin{abstract}
The teaching performance on gender and sexuality issues in public schools involves a set of delicate balances. It involves recognizing that the conceptual categories we use for talking about these themes are also categories of political action and moral regulation. It involves perceiving the school as a public education space. The article analyzes these issues from the ethnography of school scenes, and shows the importance of addressing gender and sexuality in the curriculum.
\end{abstract}

* Possui graduação em Geologia e licenciatura Plena em História pela Universidade Federal do Rio Grande do Sul, mesma instituição pela qual é Mestre em Sociologia e Doutor em Educação. É professor titular da UFRGS e líder do Grupo de Estudos em Educação e Relações de Gênero (GEERGE). E-mail: <fernandoseffner@gmail.com>. 
As a result, it is contrary to movements seeking to restrict the freedom to teach and claiming that such themes would be exclusively within the family and religion's orbits towards the formation of youngsters. Key words: Gender. Sexuality. Public schools. Teacher training.

RESUMEN: La actuación docente en temas de género y sexualidad en la escuela pública implica un conjunto de equilibrios delicados. Implica reconocer que las categorías conceptuales que usamos para hablar sobre esos temas también son categorías de acción política y regulación moral. Implica percibir la escuela como un espacio de educación pública. El artículo analiza estas cuestiones desde la etnografía de las escenas escolares, y muestra la importancia de abordar el género y la sexualidad en el currículo. Como resultado, se opone a los movimientos que buscan cercenar la libertad de enseñar, y afirma que tales temas estarían en el ámbito exclusivo de la familia y de las religiones en la formación de los jóvenes.

Palabras clave: Género. Sexualidad. Escuela pública. Formación docente.

\section{Se correr o bicho pega, se ficar o bicho come}

A atuação docente para o trabalho com temas de gênero e sexualidade na escola pública comporta um conjunto de delicados equilíbrios, em particular relacionados aos modos de lidar com a norma e com os processos de normalização. Muitas vezes, ao explicar algo que nos é um tanto desconhecido ou não usual, o que em verdade fazemos é buscar "normalizar" aquilo, matando a novidade ou a diferença, e insistindo em analisar o que não conhecemos, reduzindo ao que já conhecemos. Mas a depender da postura teórica e metodológica que assumimos, podemos pensar as condições de emergência da novidade, e estabelecer conexões entre ela e o que já conhecemos, mostrando disposição para aprender com o novo. Quando as "novidades" estão relacionadas às questões de gênero e sexualidade em uma sala de aula, tudo isso se complica no cenário contemporâneo. Temos em geral um corte geracional entre o professor e os alunos, o que implica diferenças entre projetos de vida e códigos morais. Por vezes, temos também um corte de classe econômica e social entre a turma de alunos e a professora ${ }^{1}$. Todas estas clivagens tornam complexa a abordagem de temas em gênero e sexualidade em sala de aula. Sem esquecer que por vezes estamos falando de certos temas, como a homossexualidade, enquanto o movimento social LGBTQIA $+{ }^{2}$ organiza manifestações exigindo cidadania, $\mathrm{e}$ enquanto certas igrejas fazem pregações em sentido contrário à concessão de direitos a 
estas identidades. A abordagem de questões em gênero e sexualidade na escola pública brasileira instaura nos dias de hoje um clima de pânico moral, alimentado por movimentos políticos contrários à democracia, no Brasil e no mundo. Essas pressões se desatam sobre a escola, atacada por grupos como o movimento "escola sem partido" e o movimento "ideologia de gênero", além de iniciativas de militarização de escolas públicas, conforme discutido em ZAN \& KRAWCZYK (2019). Além disso, é visível a instalação progressiva na cultura escolar de uma mistura de elementos da racionalidade neoliberal, como a noção de empreendedorismo individual, com um autoritarismo religioso fundamentalista que atinge a laicidade da educação pública, tal como discutido em SEFFNER (2019).

Tais atravessamentos explicam o título deste primeiro tópico. $\mathrm{O}$ conhecido ditado "se correr o bicho pega, se ficar o bicho come" alude a uma situação aonde o que quer que façamos traz consequências complicadas. Parece não haver saídas, num campo fortemente marcado pelo cruzamento entre conhecimentos científicos, normas morais, diretrizes de políticas públicas e saberes das diferentes tradições culturais. E tudo isso frente a uma classe de alunos que em geral não é homogênea, pois composta por sujeitos com diferentes pertencimentos religiosos, oriunda de agregados familiares com diferenças em seus códigos morais e formas de organização, inserida em culturas juvenis diversas com valores políticos não convergentes, marcada por diferenças de gênero, de orientação sexual, de raça, de pertencimento religioso, de nível de consumo, de pertença política e de projetos de vida. Tal diversidade de traços é cada vez mais comum na população escolar brasileira, a partir do forte processo de inclusão de todos e todas na escola pública impulsionado pelas diretrizes da Constituição Federal de 1988. Dois conceitos nos ajudam a sair dessa verdadeira "escolha de Sofia ${ }^{3 "}$, outra metáfora forte e própria para dar o tom de situações onde o que quer que façamos não vai trazer um resultado satisfatório para todos os envolvidos. O primeiro deles é perceber a abordagem dos temas de gênero e sexualidade na escola em seu caráter agonístico. Outra disposição é orientar as estratégias pedagógicas em sala de aula pelo conceito de modus vivendi.

O caráter agonístico é dado pela compreensão de que, mais do que "ensinar" sobre gênero e sexualidade, o professor instaura na sala de aula um ambiente de debates, argumentação, intensidade de posições, envolvimento emocional com o tema, aceitando com isso o forte caráter contingente da discussão. Parte do "solo" em que a professora estruturou a atividade se torna instável ao longo de sua execução (CARVALHO, 2004). A preparação das atividades de ensino sobre temas de gênero e sexualidade deve levar em conta que estes assuntos impactam as concepções morais dos sujeitos, e, portanto, não se trata de uma discussão apenas de ordem racional ou científica, embora seja este o papel principal da escola, a inserção dos alunos nos raciocínios e na tradição científica. Um professor atento a estas dimensões organiza sua aula de modo a permitir a expressão e o diálogo sobre todas estas questões, atuando não apenas como professor, mas 
também como um adulto de referência para seus alunos (SEFFNER, 2016). Temos então uma dupla chave de qualidade na aula: a qualidade das informações científicas trazidas ao debate sobre os temas de gênero e sexualidade, e a qualidade em termos de participação e respeito dos modos de relação e discussão postos em funcionamento. Isto permite a cada um perceber que está a falar do tema e de sua própria vida, pois que na sociedade em que vivemos é em particular em torno de questões de gênero e sexualidade que recolhemos elementos para "julgar" os que nos cercam e a nós mesmos. Esse contexto configura o que Foucault chamou de "sexo rei" (FOUCAULT, 1979). Ao contrário do que muitos imaginam, as questões relativas ao sexo e ao gênero não estão escondidas em lugares escuros, e nem são objeto apenas de repressão:

\begin{abstract}
Muito mais do que um mecanismo negativo de exclusão ou de rejeição, trata-se da colocação em funcionamento de uma rede sutil de discursos, saberes, prazeres e poderes; não se trata de um movimento obstinado em afastar o sexo selvagem para alguma região obscura e inacessível mas, pelo contrário, de processos que o disseminam na superfície das coisas e dos corpos, que o excitam, manifestam-no, fazem-no falar, implantam-no no real e lhe ordenam dizer a verdade: todo um cintilar visível do sexual refletido na multiplicidade dos discursos, na obstinação dos poderes e na conjugação do saber com o prazer (FOUCAULT, 1980, p. 70-71).
\end{abstract}

A avaliação de uma boa aula sobre temas de gênero e sexualidade recai tanto na qualidade científica da informação posta em circulação, quanto na compreensão de que estes temas têm forte impacto moral. Mais ainda, gênero e sexualidade são elementos estruturantes das relações sociais, construindo hierarquias do tipo "mulheres recebem em média $30 \%$ menos do que o salário dos homens, mesmo quando no desempenho da mesma função" ou "os homens morrem em média sete anos antes das mulheres no Brasil". A existência social e individual de cada um e cada uma está posta em cena quando debatemos em aula temas em gênero e sexualidade, e isso mostra a importância desse debate na escola, como local que faz diferença na vida dos jovens. Tanto quanto o domínio de um conjunto de informações científicas sobre o tema, os debates em gênero e sexualidade acionam os projetos de vida (casar, ter filhos, não casar, permanecer solteiro ou solteira, pensar acerca do agregad o familiar em que se vive e estabelecer um novo olhar sobre ele etc.) e suas relações de amizade (compreender o colega, entender porque me aproximo mais deste ou daquele, porque sinto aversão a certos gestos de carinho entre pessoas do mesmo sexo etc.), bem como elementos importantes de seus pertencimentos religiosos. As religiões têm nas questões de gênero e sexualidade um ponto forte na estrutura dos seus códigos de valores, e introduzem a noção de pecado em relação a certos comportamentos, muitos dos quais a estrutura jurídica não criminaliza, pois não constituem um atentado à vida, nem a própria nem a dos demais, como é o caso da homossexualidade.

O segundo conceito que ajuda na abordagem destes temas em sala de aula é o de modus vivendi (SEFFNER, 2017). Sua importância está em assumir que a escola tanto se 
envolve na alfabetização científica quanto na educação para as relações sociais, o que implica atenção aos processos de socialização e sociabilidade, próprios da cultura escolar. Pensando a escola como um espaço público, reforça-se a garantia de que cada um possa expressar suas diferenças e ser respeitado. É na escola que se aprende o valor do respeito pelas garantias constitucionais da liberdade de crença, de consciência e de livre manifestação de ideias. É nela também que aprendemos a diferença entre liberdade de expressão e manifestação de discursos de ódio, que colocam a vida dos outros em risco, em frases do tipo "é melhor um filho morto do que um filho gay". Estas categorias são pensadas como parte fundamental da organização da sociedade, capazes de garantir o respeito à diferença e a construção de um modus vivendi de justiça social. $\mathrm{O}$ traço fundamental da noção histórica de modus vivendi é a capacidade de construir acordos entre indivíduos e grupos cujas opiniões diferem, elemento imprescindível para a efetivação da democracia. A escola é a primeira instituição onde as crianças e os jovens vão interagir com outros indivíduos com marcadores identitários diversos: são colegas com diferenças no pertencimento religioso; com diferenças de posição política e partidária; que se inserem em diferentes culturas juvenis (são roqueiros, funkeiros, adeptos do hip-hop ou do K Pop, da música tradicionalista, do pagode, das canções de protesto, da bossa nova, isso só para ficar nos ritmos musicais, que revelam muito do pertencimento às culturas juvenis no Brasil); com diferenças de gênero e de orientação sexual; com diferenças de projeto de vida; com diferenças de geração; com diferenças corporais (no caso brasileiro, o convívio na mesma sala de aula de alunos da cultura surda, alunas com deficiência visual, cadeirantes, alunos com diferentes tipos de necessidade de educação especial, todos convivendo com os supostos "normais"); alunas com diferenças de pertencimento a classe social e econômica; com diferentes pertencimentos étnicos e raciais; com diferentes pertencimentos regionais etc.

Para além do domínio da informação científica, a escola é cada vez mais um importante lugar de educação para as relações sociais, aprendendo quais os melhores modos de estabelecer o convívio em meio a tantos marcadores identitários diferentes. No estudo dos temas de gênero e sexualidade a educação para as relações sociais joga um papel extremamente importante, e por conta disso esse estudo deve ser feito em conexão com a educação em e para os Direitos Humanos, prevista na Constituição Federal (BRASIL, 1988) e na Lei de Diretrizes e Bases (BRASIL, 1996), bem como regulamentada em leis ordinárias em numerosos estados e municípios. Cabe à escola papel importante de cultivar um ambiente em que todas as pessoas tenham a oportunidade de transitar sem serem hostilizadas em razão de suas preferências de gênero ou de orientação sexual, bem como de suas preferências de pertença religiosa. Certamente é um objetivo difícil, mas o trabalho com estes temas deve visar a construção de uma cultura escolar que manifeste o mais alto grau de respeito simultaneamente pelas diferenças de gênero, de orientação sexual e de pertencimento religioso. Acostumados que estamos a uma equação em que maior 
liberdade de expressão religiosa implica necessariamente menor liberdade de expressão sexual, e vice-versa, claro está que este objetivo é algo difícil de atingir, pois a escola está inserida em uma sociedade marcada por fortes processos de exclusão e desrespeito a estes atributos identitários, tanto os religiosos quanto aqueles de gênero e sexualidade. Somos uma sociedade muito homofóbica e também de muita intolerância religiosa. Mas é na direção de superar essas marcas que o trabalho docente deve se mover, é esta a direção que assegura densidade democrática na proposta político pedagógica.

Vale lembrar também que a escola tira nota baixa em inúmeras pesquisas que tratam da produção da discriminação em atributos de gênero e sexualidade. É o que se verifica, para o caso brasileiro, em particular em duas pesquisas, feitas pela Unesco (CASTRO, ABRAMOVAY e SILVA, 2004) e pela Fundação Perseu Abramo (VENTURI \& BOKANI, 2011). Na pesquisa da Fundação, os resultados mostram uma situação em que pontos positivos e negativos se mesclam no ambiente escolar. Se por um lado a escola aparece como ambiente onde a discriminação e a violência contra gays, lésbicas, travestis e transexuais é forte, por outro lado o aumento do nível de escolaridade tem relação direta com a diminuição do preconceito em relação aos atributos de gênero e sexualidade:

\footnotetext{
Segundo a pesquisa da Fundação Perseu Abramo, a variável que mais determina o nível de preconceito das pessoas é a escolaridade. Há uma grande diferença de preconceito entre quem nunca foi à escola e quem concluiu o ensino superior (em \%). "Isso mostra como a escola faz diferença no combate à homofobia. Só a escolaridade maior não resolve o preconceito, mas influencia fortemente a formação dessas pessoas", afirma [Gustavo Venturi]. Para o pesquisador, além de ser um espaço para convivência com as diferenças, a escola pode promover o debate de forma educadora e transformar a percepção de preconceitos arraigados à população. O estudo revelou que o brasileiro ainda não é tolerante com as preferências sexuais de familiares, de colegas de trabalho ou de vizinhos: um quarto dos entrevistados admitiu ter preconceito e agir de forma homofóbica .
}

Este dado da pesquisa mostra que a preparação das docentes para lidar com as situações que envolvem diversidade de gênero e sexualidade na escola é fundamental para o sucesso na diminuição do preconceito, e para a compreensão do espaço público como local de negociação das diferenças. Estud o feito pela Unicef no Chile, envolvendo escolas públicas e privadas de várias cidades, chegou a conclusão semelhante, indicando que educação de qualidade pode ajudar muito a reverter os níveis de preconceito e discriminação, não apenas em atributos de gênero e sexualidade, mas também aqueles que envolvem nacionalidade, etnia, deficiência e pertencimento religioso (UNICEF, 2011). Vale lembrar que a escola moderna é um equipamento cultural que está historicamente comprometido com a formação de homogeneidades, sejam elas de nacionalidade (a escola sempre esteve envolvida na produção das lealdades nacionais); de raça etnia (no geral as instituições escolares ao apresentar a formação de um povo ou nação colocam certas raças como mais importantes do que outras); de gênero e sexualidade (a escola 
auxilia a promover a formação de cidadãos heterossexuais e com papéis bem definidos de gênero, onde o homem é destinado às tarefas da esfera pública e a mulher voltada ao ambiente doméstico); dentre outras produções hegemônicas e homogêneas. Portanto, inverter o sinal, e construir uma escola que se ocupe com o conhecimento, a valorização e o respeito pela diversidade cultural é algo novo, e tem impactos na densidade democrática de qualquer país.

\section{Observando a sala de aula e suas interações}

Estabelecidos estes dois grandes propósitos políticos, ancorados em dois conceitoso caráter agonístico do ensino de temas de gênero e sexualidade e o objetivo de construção de um modus vivendi com forte capacidade para a construção de acordos entre indivíduos e grupos cujas opiniões diferem - passamos à abordagem do tema. O que segue está estruturado de forma a costurar algumas categorias conceituais - norma, heteronormatividade, homofobia, adulto de referência, direitos humanos - com a apresentação e análise de duas cenas coletadas, pensando nelas como os principais elementos para uma abordagem do ensino de questões de gênero e sexualidade em conexão com os direitos humanos. Antes de passar às cenas, vale um comentário sobre sua coleta.

O texto investe na etnografia de cenas escolares, método que faz referência a etnografia cultural, coletadas em escolas públicas da cidade de Porto Alegre, nos últimos anos, no âmbito de dois projetos de pesquisa ${ }^{5}$, na tentativa de surpreender a emergência e o encaminhamento dado a questões ligadas principalmente à sexualidade, mas sem deixar de perceber seus contornos de gênero. O estímulo à coleta de cenas escolares está pensado como estratégia de formação permanente do professor ${ }^{6}$. Concluída a formação inicial, feita geralmente numa instituição de nível superior, a professora ingressa numa rede escolar, e ao longo dos anos de magistério vai acumulando um saber docente. Este saber docente refere-se ao conjunto de aprendizados que o dia a dia da docência lhe proporciona. Ele é em geral um saber pouco sistematizado, pois infelizmente muitos docentes não têm oportunidade de refletir sobre as situações de sala de aula.

Conforme muitos autores já discutiram, a experiência não é o que nos acontece, mas o que fazemos com o que nos acontece (LARROSA, 1996). A maioria dos professores apenas "sofre" os anos de magistério e reflete pouco sobre os acontecimentos que poderiam constituir sua experiência. Daí vem certa sensação de esvaziamento após anos de docência. No sentido de formar uma docente pesquisadora, capaz de refletir sobre sua prática, a proposta é de constituir um acervo de cenas escolares, que servirão como matéria prima para reflexões capazes de gerar uma experiência docente. As cenas escolares são os dados que alimentam as pesquisas e para tanto necessitam ser convenientemente anotadas, depois discutidas, analisadas e colocadas em conexão com leituras e discussões 
acadêmicas. A sala de aula pode ser vista como laboratório, onde o professor vai coletando cenas, situações, e anotando num diário de campo, para futura análise. Podemos fazer a etnografia da sala de aula tendo em vista diferentes propósitos, e no caso do presente texto o que nos interessa são cenas que envolvem questões de gênero e sexualidade, mesmo quando se trata de atividades em que este não foi o propósito original.

Partindo dos dois princípios - tomar a sala de aula como local privilegiado de investigação e investir na formação de um professor pesquisador - estruturamos projetos de pesquisa que visavam aprimorar a etnografia de sala de aula. A observação das cenas e seu apontamento exigem certa organização, tal como se dá na coleta de dados em qualquer pesquisa ou mesmo num laboratório. A professora precisa tomar notas acerca das cenas de modo adequado para posteriormente possibilitar sua análise. Uma cena anotada não vale por si, mas vale pela especulação teórica que se pode produzir a partir dela. Em nosso caso, o que desejamos é capturar cenas onde atributos de gênero e sexualidade estiveram em xeque, produzindo atritos nos modos de socialização e sociabilidade de docentes e discentes. Queremos flagrar também elementos de diversidade cultural, evitando considerar que os alunos são todos iguais, que a classe de alunos é homogênea. A etnografia que produziu as cenas é localizada, em escolas e contextos específicos, e também datada. Mas o que dali se discute pode servir para pensar situações de sala de aula em muitos outros locais. Com isso, anotamos o episódio específico, mas valorizamos os componentes sociais, que fazem com que cada caso não seja um caso, conforme discutido em FONSECA (1999).

Vale lembrar que são apenas os professores e professoras que vivenciam de modo intenso e continuado as cenas e situações de sala de aula. Desta forma, são espectadores privilegiados, que podem anotar, analisar e posteriormente debater os significados do que ocorre, com a ajuda de referências teóricas. Se as professoras não fizerem isso, seguiremos vivendo num mundo em que políticos e gestores (e também jornalistas, psicólogos, padres, pastores, advogados, juízes, médicos etc.) sentem-se à vontade para dar opiniões sobre como deve ser uma sala de aula - e isto vale especialmente para os temas de gênero e sexualidade. Explicados os pontos essenciais da técnica, passamos a apresentação e debate das cenas.

\section{É mais fácil construir um menino do que consertar um homem}

Outro ditado popular que reflete a importância das questões de gênero. Quem diz isso certamente não criou filhos e nem é professora. Tão difícil quanto "consertar" um homem ou uma mulher é "construir" um menino ou uma menina. A escola tem parcela importante no esforço de construção de meninos e meninas, e isso deve ser feito tomando-se em conta que ela é um espaço público e ao mesmo tempo um laboratório 
de preparação para a vida plena na esfera pública. Ou seja, sobre a criança e o jovem não recaem algumas penalidades da justiça, por conta do limite da maioridade. É ao longo do percurso escolar que as sucessivas idades que indicam conquista da autonomia vão se realizando, e o currículo escolar acompanha isso: aos 12 anos não se é mais considerado criança do ponto de vista da responsabilidade penal, há possibilidade de aplicação de penas diferenciadas; aos 14 anos está a possibilidade de consentimento para o ingresso na vida sexual, e a partir dessa idade se pode trabalhar legalmente como aprendiz, podendo não ser mais considerado trabalho infantil; aos 16 anos é possível votar nas eleições e trabalhar sem ser na condição de aprendiz. Desta forma, a escola é um espaço público original, pois ela já se regra pelos modos do espaço público, mas ao mesmo tempo é um laboratório de preparação para a vida plena no espaço público, quando crianças e jovens já serão adultos e poderão ser responsabilizados inteiramente por seus atos. Por conta disso, na escola, a ênfase é na educação, mais do que na punição ou judicialização dos atos.

As diferenças de gênero e sexualidade são visíveis a todo momento na escola. Mesmo quando a atividade solicitada pela professora não envolve esses temas, estas diferenças podem aparecer, e em muitas oportunidades é adequado que possam ser problematizadas. As duas cenas abaixo foram colhidas em escolas públicas de Porto Alegre, e possibilitam pensar o trabalho com a norma heterossexual, que organiza as identidades em gênero e sexualidade. A primeira cena envolve alunos e alunas do ensino fundamental, e a segunda envolve alunos e alunas do ensino médio.

No âmbito de um programa de formação docente continuada para professores de História e Geografia, eu e um colega da Geografia visitamos hoje uma escola de ensino fundamental, para acompanhar a atividade planejada por duas professoras como trabalho de finalização do curso. Foram selecionadas duas turmas de sexto ano do ensino fundamental, crianças em torno de 10 anos de idade. As meninas das duas turmas ficaram em um grupo, e os meninos em outro. Foram colocados os grupos em salas separadas, e cada uma das salas estava quase vazia, com poucas carteiras e cadeiras. Eu observei a sala dos meninos, meu colega a das meninas. Cada professora coordenou as ações em uma das salas. A tarefa era a mesma para os dois grupos. Tendo recebido alguns rolos de papel higiênico, barbante, fita adesiva, cola, pincel e tinta têmpera, cada grupo teve meia hora para fazer a ocupação do espaço, tema que havia sido trabalhado em aulas de História e Geografia com as turmas. Decorrido o tempo, meninos e meninas saíram das salas, e foi feito um sorteio para saber qual seria a primeira sala visitada pelo grupo todo. A dos meninos foi sorteada. Eles apresentaram então para as meninas o que tinham feito. Assim que foi dada a instrução, do modo mais atabalhoado possível, em que todos queriam coordenar todos, e ninguém queria obedecer a ninguém, eles começaram a traçar caminhos, ruas e avenidas, pelo chão, pelas paredes e até mesmo no teto da sala, subindo uns nos ombros de outros. Além de desenhar caminhos em linha reta ou em curvas, subindo e descendo paredes, o que foi facilitado pelos rolos de papel higiênico e pelos barbantes, eles fizeram setas, muitas setas, indicando as mais variadas direções. Depois de muita coisa ter sido colada em todas as paredes, chão e teto, eles usaram a tinta para pintar mais setas, esquinas, direções. Quando um caminho cruzava com outro, eles imitaram viadutos e pontes. Alguns tiveram a ideia de 


\begin{abstract}
pintar uma legenda que lembrava caminhos de ferrovia, então tínhamos praticamente estradas e ferrovias para todo lado. Feita a apresentação, fomos para a sala das meninas, e elas explicaram como haviam trabalhado, e o que haviam feito. Dada a instrução, as meninas buscaram se organizar em grupos, e dividiram o material entre os grupos. Feito isso, cada grupo ocupou um espaço da sala, cercou com papel e barbante, e desenhou em seu interior objetos como cadeiras, mesas, livros, tigelas. Os cantos da sala foram os preferidos, e ali elas aproveitaram as paredes para estruturar armários e prateleiras de papel e barbante e fita adesiva. As que ficaram pelo meio da sala aproveitaram as poucas classes e cadeiras para fazer com que a ocupação do espaço ganhasse volume. Apresentada a sala das meninas e dadas as explicações do modo como tinham se organizado para a tarefa, alguns meninos logo comentaram "as gurias fizeram casinhas", claramente em tom depreciativo. Elas reagiram, dizendo que o que eles tinham feito era uma bagunça, cada um por si, trilhas de papel para todo lado, "uma coisa sem noção" para usar a expressão mais corrente delas. Tivemos alguns momentos de bate-boca entre meninos e meninas, e uma das professoras propôs a organização do debate, e perguntou em que sala gostariam de ficar para a conversa, na dos meninos ou naquela das meninas. Sem hesitação, meninos e meninas decidiram ficar na sala das meninas, reconhecendo que ali havia local para sentar em grupos (Diário de campo, outubro 2013).
\end{abstract}

Da cena acima narrada, queremos recolher alguns elementos. $\mathrm{O}$ primeiro e mais evidente é a diferença no quesito ocupação do espaço num recorte de gênero, ou seja, meninos e meninas trataram de ocupar o espaço de formas muito diferentes. Não é difícil perceber que os meninos tomaram o espaço como espaço público, espaço de circulação, enquanto as meninas tomaram o espaço como espaço doméstico ou privado, para viver, mais do que para circular. Também diferiu muito o modo de organização dos grupos. As meninas dedicaram um tempo inicial a distribuir-se em subgrupos e a repartir o material. Os meninos iniciaram a tarefa de modo individual, embora todos na mesma direção, com o mesmo propósito. Cada um se converteu em um pequeno empreendedor e negociou com os demais apenas quando a tarefa já estava em andamento, por conta dos cruzamentos na ocupação do espaço. Chama a atenção o comentário dos meninos, reconhecendo no que as meninas haviam feito uma típica marca do gênero feminino: "brincar de casinha". Por outro lado, as meninas criticaram a ocupação do espaço feita pelos meninos, enfatizando a desorganização, mas poderiam talvez ter dito que os meninos estavam "brincando de carrinho", típica atividade masculina. Colhidos pela proposta da atividade, de ocupação do espaço, foi visível que as diferenças entre os dois grupos estavam muito relacionadas aos pertencimentos de gênero. Tal atividade mostrou que gênero é um elemento estruturante das relações sociais, e a escola não pode perder oportunidades para debater esse elemento, inclusive porque ele surge de modo vigoroso em muitas oportunidades, como foi a cena colhida. Talvez alguns dos alunos e alunas viessem de famílias onde normalmente se afirmava que mulheres devem ficar em casa e homens ir para rua. Entretanto, a escola é espaço público, e se rege por outro princípio, a saber, a igualdade entre homens e mulheres, aliás, um princípio constitucional. Dessa forma, o debate acerca da atividade é bem-vindo no espaço escolar, mesmo que algum dos alunos 
escute ali opiniões que conflitam com aquelas manifestadas por seus pais ou pelas lideranças religiosas. É assim que se conquista autonomia pessoal e intelectual, observando a diversidade de pontos de vista no mundo e formando um juízo próprio. Crianças não vão à escola para aprender lá o mesmo que aprendem em casa, se fosse assim não precisariam ir à escola. Questões de sexualidade estiveram ausentes nessa primeira atividade, mas na cena a seguir elas já se fazem presentes.

Hoje fui até a escola onde lecionam duas professoras que fizeram o Curso de Aperfeiçoamento em Educação, Sexualidade e Relações de Gênero, assistir uma intervenção pedagógica preparada por elas. A atividade faz parte da semana de integração dos novos alunos na escola, que é exclusiva de ensino médio, e recebe no primeiro ano alunado de muitas escolas de vários bairros de Porto Alegre. Meninos e meninas foram separados em dois grupos, e cada grupo foi para uma sala diferente e distante. Os grupos tiveram 20 minutos para que as meninas se vestissem de meninos, e os meninos se vestissem de meninas. Isso havia sido combinado antes e todo mundo trouxe roupas. Além do que foi trazido, as professoras de teatro providenciaram também figurinos e adereços, dispostos em cada uma das salas. Decorrido o tempo, saíram das duas salas, ao mesmo tempo, os meninos e as meninas. O modo como cada grupo se fantasiou foi marcadamente diferente. As meninas se vestiram de jogadores de futebol, marinheiros, motoqueiros, desleixados, hip-hop, intelectual nerd, gaúcho, ciclista, motorista de caminhão, médico, advogado, bombeiro, lavrador etc. Enfim, de modo improvisado ou com roupas mais adequadas, as meninas mostraram uma variedade de tipos masculinos. Os meninos estavam todos usando saias, vários deles com perucas, salto alto, maquiagem berrante e borrada, mas com um traço evidente em comum: literalmente todas as fantasias tinham um apelo que as fazia parecer prostitutas. Até mesmo um menino trajando de freira estava provocante, o hábito arregaçado acima dos joelhos, e o menino com a boca pintada de vermelho. Não apenas nas roupas, que ganharam um tom sexy e provocante, mas também nas atitudes, que eram debochadas e "oferecidas", todos imitavam, caminhavam, falavam e se comportavam parecendo prostitutas. No meio disso tudo, riam e gargalhavam, o que também contrastou com a apresentação das meninas, que riam, brincavam, mas não de forma debochada e nem com apelo sexual forte. Passado o impacto inicial, várias meninas fizeram o seguinte comentário, com variações: "para os guris, mulher é sempre puta". As professoras que haviam me convidado ficaram muito desapontadas e constrangidas com a atividade, pois imaginavam algo completamente diferente, onde seria possível debater sobre questões de gênero, profissões e carreiras de homens e mulheres. A atividade pode não ter servido exatamente aos propósitos de integração das turmas, como imaginado, mas serviu para levantar questões que com certeza devem ser debatidas ao longo do ano (Diário de campo, março 2009).

Nessa cena, mais do que o aspecto de gênero, queremos destacar questões de sexualidade, que a nosso ver podem ser analisadas a partir de dois conceitos. O primeiro deles é o recurso ao deboche, muito frequente nas performances masculinas e muitas vezes denunciado pelas meninas em expressões como "os guris são crianções”, "os guris são bobalhões", "os guris não levam nada a sério" e algumas variantes (SEFFNER, 2013). O deboche torna difícil debater sobre o tema, tal como experimentado em muitas situações de oficinas com estudantes, pois os alunos, quando questionados pelas alunas, em 
geral adotavam como saída variações da expressão "nós estamos brincando, vocês não percebem que estamos brincando, a gente está se divertindo, vocês levam tudo a sério, deixa a gente brincar". Com esse procedimento, e aqui temos o sentido de termo deboche que nos interessa, os meninos menosprezam a atividade, zombam e escarnecem. Em outras palavras, eles fazem a atividade proposta, mas fazem de uma forma que impede ou limita seriamente o debate. Nessa medida, eles tornam o terreno todo da atividade muito instável e dificultam a ação pedagógica da professora.

O segundo conceito que pode nos ajudar a analisar o acontecido é o de paródia. Estas formas que acabamos de nominar como debochadas podem ser vistas também por outro ângulo, uma outra forma de destacar a norma, fazendo dela um arremedo ou abordagem satírica. Podemos qualificar este procedimento como o da utilização do recurso da paródia, de amplo uso entre as culturas juvenis (SOARES, 2005). Conforme MOSER (1993), temos na paródia um elemento de imitação que busca produzir efeito cômico. A imitação pressupõe a existência de um modelo, no caso aqui se pode pensar na imitação da heteronormatividade, da norma em termos de gênero e sexualidade. Mas este efeito cômico traz a operação de rebaixar e ridicularizar o suposto modelo que está sendo parodiado. Desta forma, podemos dizer que os meninos não estão exatamente zombando da atividade, mas explicitamente colocando o gênero feminino num patamar de inferioridade, através do cômico da paródia. Mas, ao fazer isso, eles permitem a visibilidade da norma heterossexual, que opera num registro binário tanto de gênero (masculino versus feminino) quando de sexo (heterossexual versus homossexual). Sempre que temos um registro binário, um dos polos busca se afirmar como superior frente ao outro. Este elemento permite destacar outro aspecto que a atividade colocou em evidência. Um dos recursos para inferiorizar o feminino é reduzi-lo a um único traço, no caso, pensar a mulher exclusivamente como sexo, daí como prostitutas. As meninas ampliaram a visão de masculino, fornecendo muitos modelos possíveis de homens, em geral ligados a diferentes profissões. Os meninos fizeram uma redução do feminino a um único traço, o da sexualidade, e ainda mais associado a uma profissão da qual se diz que é "a mais antiga do mundo". Em resumo, nossa posição é de que a atividade permitiu enorme visibilidade da norma, que em geral se mantém silenciosa e operante. Claro está que a visibilidade veio através da paródia, mas isso também revela um importante modo de relação entre os gêneros, no qual os homens tomam a mulher como sinônimo de sexo. Em nossa sociedade, aliás, quando se diz que existe sexo em algum lugar (por exemplo, nas propagandas de sabonete), o que estamos dizendo é que existem mulheres neste local, e aqui retomamos a citação de Foucault acima posta, a lembrar que a sexualidade brilha na superfície de quase todos os artefatos culturais em nossa sociedade.

Voltamos ao título do texto para encerrar estas considerações. A norma, que no caso das questões de gênero e sexualidade podemos nomear como heteronormatividade, ou heterossexualidade compulsória, age de modo silencioso. Por conta disso, somos em 
geral capturados para falar dos diferentes - os meninos afeminados, as meninas que se parecem como homens, as travestis e transexuais que agora se assumem na escola e quase não problematizamos a norma. Mas com atenção a cenas escolares, podemos flagrar momentos em que a norma fica exposta, e pode ser problematizada. O enorme desafio na abordagem dos temas de gênero e sexualidade na sala de aula talvez resida naquilo a que Deleuze chama a atenção:

Trata-se de inventar novos modos de existência, segundo regras facultativas, capazes de resistir ao poder bem como se furtar ao saber, mesmo se o saber tenta penetrá-los e o poder tenta apropriar-se deles. Mas os modos de existência ou possibilidades de vida não cessam de recriar, de surgir novos (DELEUZE, 1992, p. 116).

Voltamos a afirmar: a experiência escolar precisa ser pensada em conexão entre a oportunidade de alfabetização científica e a oportunidade de educação para as relações sociais. No caso que nos propomos analisar, interessam as relações sociais onde os marcadores de gênero e sexualidade entram em ação. A escola deve investir numa educação para as relações de gênero e sexualidade que se paute pelos ideais republicanos e valores do espaço público, mais do que pelas tradições familiares. Aqui já temos um delicado equilíbrio, explicar a pais e mães que seu filho ou filha vai aprender na escola conteúdos que podem estar em pouca sintonia com o que ele aprendeu em casa, e que isso não tem nada de errado, pois a educação escolar não é a continuação da educação doméstica ou familiar, assim como a medicina pública não é a continuação da medicina praticada em casa na base das tradições, e assim como a justiça pública não é pautada pelas disposições familiares. A escola está comprometida com a formação científica e com o preparo para a vida no espaço público, e isso implica necessariamente certo grau de tensão com os valores familiares. Esse é o delicado ponto em que movimentos como o movimento "escola sem partido" e o movimento "ideologia de gênero" atacam a cultura escolar, pretendendo que ela funcione a reboque dos desejos das famílias e das religiões. Ao insistir que a escola deve se pautar por valores de equidade, nada mais estamos fazendo do que repetir os princípios da educação nacional, claramente indicados na Constituição Federal de 1988: igualdade de condições para o acesso e permanência na escola; liberdade de aprender, ensinar, pesquisar e divulgar o pensamento, a arte e o saber; pluralismo de ideias e de concepções pedagógicas; gestão democrática do ensino público.

A norma precisa ser provocada para se poder dela falar. Muitas das atividades feitas em sala de aula, de modo intencional ou não, provocam a norma, conforme quisemos mostrar nas duas cenas. Cabe ao professor a agilidade intelectual e pedagógica para fazer destes momentos oportunidades de estudo e de educação para as relações sociais. Cabe à professora perceber que os alunos inventam a todo momento novos modos de vida; as novas gerações não vieram ao mundo para seguir na íntegra os caminhos que lhes 
ensinamos, elas vão inventar o mundo e podem não aceitar todas as nossas interpretações do passado, todos os códigos de valores que nos preocupamos em transmitir. As novas gerações fracassariam na vida se fizessem tudo da forma como lhes prescrevemos. Rorty (2007), comentando as ideias de Nietzsche acerca dessa produção de novas formas de vida, diz:

Fracassar como poeta - e portanto, para Nietzsche, fracassar como ser humano - é aceitar a descrição de si mesmo feita por outra pessoa, é executar um projeto previamente preparado, é escrever, no máximo, variações elegantes sobre poemas escritos no passado (RORTY, 2007, p. 64).

De todos os delicados equilíbrios que um professor ou professora precisa enfrentar ao abordar temas de gênero e sexualidade na escola, esse nos parece o mais complexo, a saber: trazer informações científicas ao debate, saber lidar com a carga moral que estes temas inevitavelmente têm, saber lidar com sua própria posição moral no tema, respeitar a posição das famílias mas ao mesmo tempo avançar valores que dialogam com a noção republicana de espaço público, e compreender que as novas gerações vão inventar novos modos de vida, em diálogo com a tradição. A interação nesse jogo de equilíbrios complexos implica estratégias de cumprir, resistir e transgredir a heteronormatividade. Por conta disso tudo, só temos a elogiar os professores e as professoras que se dispõem a atuar na educação em temas de gênero e sexualidade. São adultos de referência, cada vez mais necessários nestes novos tempos em que movimentos sociais de índole autoritária e conservadora buscam asfixiar o debate em torno desses marcadores sociais da diferença, que, se não são postos em debate, originam situações de desigualdade e violência.

Recebido em: 19/05/2020 e Aprovado em: 25/05/2020

\section{Notas}

1 De modo a alertar o leitor para a composição do magistério entre homens e mulheres, o que faz diferença nas cenas narradas e nos encaminhamentos dados em sala de aula, vamos alternar na escrita os termos professor, professora, o docente, a docente. Fazemos o mesmo com aluno, aluna.

2 LGBTQIA+ é a sigla mais corrente para designar um conjunto de identidades de gênero e sexualidade que inclui lésbicas, gays, bissexuais, travestis e transexuais e pessoas trans, sujeitos que se reconhecem como queer, pessoas intersex, assexuais e outras identidades nesse campo, indicadas pelo sinal +.

3 Para conhecer a história que deu origem a esta conhecida expressão recomendamos a leitura do romance $A$ Escolha de Sofia, de William Clark Styron, publicado no Brasil pela Editora Record e pela Geração Editorial.

4 Informação disponível em: http://ultimosegundo.ig.com.br/educacao/escola+e+determinante+para+o+fim+da+homofobia+diz+pesquisador/n1596978678723.html (último acesso em 22 de abril de 2020). 
5 Refiro-me aqui ao projeto de pesquisa intitulado "Ensino Religioso no interior do estado laico: análise e reflexões a partir das escolas públicas de Porto Alegre", que visa analisar as estratégias educacionais e os conteúdos presentes nas aulas de ensino religioso em um conjunto de escolas públicas estaduais do município de Porto Alegre, e ao projeto "Consolidando o pensamento sobre direitos humanos na perspectiva dos países do Sul: ações e reflexões em torno de a) direitos sexuais; b) acesso a medicamentos e propriedade intelectual e c) liberdades laicas", que se propunha a uma reflexão teórico-conceitual interdisciplinar na perspectiva dos direitos humanos sobre as três temáticas específicas. Nos dois projetos tivemos intenso trabalho de etnografia de cenas escolares, gerando um banco de dados.

6 Parte do que segue sobre a etnografia de cenas escolares é feita seguindo de perto minha exposição no âmbito do Curso de Aperfeiçoamento Educação para a Diversidade, ofertado em regime de EAD em 2010 pela Faculdade de Educação UFRGS. Mais informações em http://www.ufrgs.br/educacaoparaadiversidade/ sobre-o-curso (último acesso em 19 de abril de 2020)

\section{Referências}

BRASIL. Constituição da República Federativa do Brasil de 1988. Brasília, 1988. Disponível em http:// www.planalto.gov.br/ccivil_03/constituicao/constituicaocompilado.htm Acesso em 5 de março de 2020.

BRASIL. Lei n⿳0 9.394 de 20 de dezembro de 1996, estabelece as diretrizes e bases da educação nacional. Brasília, 1996.

CARVALHO, Alonso Bezerra de. O Apolíneo e o Dionisíaco: O caráter agonístico da educação. Brasília: Revista Sul-Americana de Filosofia e Educação, Brasília, n. 2, volume 1, pp. 1-5, maio/out. 2004. Disponível em https://periodicos.unb.br/index.php/resafe/article/view/3901/3571 Acesso em 5 de abril de 2020

CASTRO, Mary Garcia; ABRAMOVAY, Miriam \& SILVA, Lorena Bernadete da. Juventudes e sexualidade. Brasília: UNESCO Brasil, 2004.

DELEUZE, Gilles. Conversações. Rio de Janeiro: Editora 34, 1992.

FONSECA, Claudia. Quando cada caso NÃO é um caso: pesquisa etnográfica e educação. Rev. Bras. Educ. [online], n.10, pp. 58-78, jan/abr de 1999. Disponível em http://anped.tempsite.ws/novo_portal/rbe/ rbedigital/RBDE10/RBDE10_06_CLAUDIA_FONSECA.pdf Acesso em 5 de abril de 2020

FOUCAULT, M. História da Sexualidade I: A vontade de saber. Rio de Janeiro: Graal: 1980.

FOUCAULT, Michel. Não ao Sexo Rei. In: FOUCAULT, Michel. Microfísica do Poder. Rio de Janeiro: Edições Graal, 1979. Pp. 229-242

LARROSA, Jorge. Literatura, experiência e formação. In.: COSTA, Marisa Vorraber. (org.). Caminhos investigativos: novos olhares na pesquisa em educação. pp. 133-161, Porto Alegre: Mediação, 1996.

MOSER, Walter. A paródia: moderno, pós-moderno. Remate de Males, Campinas, volume 13, pp. 133$145,1993$.

RORTY, Richard. Contingência, ironia e solidariedade. São Paulo, Martins Fontes, 2007.

SEFFNER, Fernando. Sempre atrás de um buraco tem um olho: racionalidade neoliberal, autoritarismo fundamentalista, gênero e sexualidade na Educação Básica. Práxis educativa, Ponta Grossa, v. 15, pp. $1-19,2020$. 
SEFFNER, Fernando. A escola e a construção de um "modus vivendi" de valorização da diversidade e de respeito aos diferentes modos de ser. In RIOS, Jane Adriana Vasconcelos Pacheco (Org.). Diferenças e desigualdades no cotidiano da educação básica. Campinas, Mercado de Letras, 2017, p. 227-256.

SEFFNER, Fernando. Escola pública e professor como adulto de referência: indispensáveis em qualquer projeto de nação. Educação Unisinos, Vale dos Sinos, v. 20, nº 1, pp. 48-57, janeiro/abril de 2016.

SEFFNER, Fernando. Sigam-me os bons: apuros e aflições nos enfrentamentos ao regime da heteronormatividade no espaço escolar. Educação e Pesquisa, São Paulo, v. 39, nº 1, pp. 145-159, janeiro/ março de 2013.

SEFFNER, Fernando. Um bocado de sexo, pouco giz, quase nada de apagador e muitas provas: cenas escolares envolvendo questões de gênero e sexualidade. Revista Estudos Feministas, Florianópolis, v. 19, n. 2, pp. 561-572, maio/agosto de 2011.

SOARES, Rosânge.la de Fátima Rodrigues. Namoro MTV: juventude e pedagogias amorosas/sexuais no Fica Comigo. Tese de doutorado. Universidade Federal do Rio Grande do Sul, Porto Alegre, 2005.

UNICEF. La Voz de los Niños, Niñas y Adolescentes y Discriminación. Santiago do Chile, 2011 Disponível em http://www.unicef.cl/pdf/PPTLaVozDiscriminacion2011.pdf Acesso em 22 de abril de 2020.

VENTURI, Gustavo Venturi \& BOKANI, Vilma. (Orgs.). Diversidade Sexual e Homofobia no Brasil. São Paulo: Editora Fundação Perseu Abramo, 2011.

ZAN, Dirce \& KRAWCZYK, Nora. Ataque à escola pública e à democracia: notas sobre os projetos em curso no Brasil. Revista Retratos da Escola, Brasília, v. 13, n. 27, p. 607-620, set./dez. 2019. 